\title{
Mathematical modeling in economics for selection of optimum investment solution
}

\author{
Arthur Alukhanyan ${ }^{1, *}$ and Olga Panfilova ${ }^{1}$ \\ ${ }^{1}$ Don State Technical University, sq. Gagarina, 1, 344003 Rostov-on-Don, Russia
}

\begin{abstract}
This work is devoted to development of economic and mathematical models for selection of the optimum investment solution. Moreover, it states the basis for development of model examples and correction of the model considering the results obtained in the examples. In the work the problem is set for selection of the investment sources and objects, which is limited to the linear programming problem. The controlled variable and basic limitations simulating real credit and monetary relations are distinguished in the provided model. The discounted profit obtained from implementation of the optimum investment portfolio is considered as a target function. The economic and mathematical model presented in the article allows finding the optimum investment solution within the limits of the credit and monetary relations taking place both at the micro- and macroeconomic level.
\end{abstract}

\section{Introduction}

In foreign scientific papers (scientific articles, monographs, etc.) address issues related to the analysis and modeling of investment processes in various sectors of the economy, including the agricultural sector. In most cases, such studies are reduced to the use of economic and mathematical modelling to solve individual problems in the field of mechanization of agricultural production. So, for example, in [1], the results of a study of the nature and characteristics of investment processes in the agricultural sector, as well as recommendations on the modernization of the mechanisms for strategic management of these processes, are considered. The purpose of the articles [2,3] is to establish a close link between investment attraction and increased agricultural output. Positive dynamics were found as a result of the analysis of the dynamics of investments in fixed assets in the agricultural sector during the analyzed period, but their fluctuations by years are observed due to the influence of factors of the external and internal environment. Scientific methods were used in the research process: modeling - to build an investment model for the development of the agricultural sector of the economy; economic and statistical - to assess the dynamics of capital investment; analysis and synthesis - to find out the reasons that cause changes in capital investment. A distinctive feature of the research [4-10] is that one of the priority tasks of improving the efficiency of mechanized processes in agriculture is

*Corresponding author: aaalukhanyan78@mail.ru 
considered the task of increasing the daily and seasonal output of the machine and tractor fleet.

However, all of these and many other works do not address the issues of developing an economic and mathematical model for choosing the optimal strategy for forming an organization's investment portfolio, while testing it on a model example.

\section{Materials and Methods}

At the stages of development and implementation of the economic and mathematical models so-called "model examples" simulating the real economic relations and demonstrating the solving model and method are used not infrequently. As a rule, it is associated with that approval and check of the mathematical model efficiency under real market conditions are rather expensive processes. Therefore, development of the model examples, which is relatively inexpensive process on the one hand, can provides the tangible results during testing of the models for their functionality and degree of utility in the real business environment on the other hand. At the same time, the model examples allow detecting "weak points" in the mathematical models, which couldn't be considered at the stage of their general development. Recently the computer modelling, which allows obtaining the optimum solution (or solutions, if many) for the developed mathematical model as soon as possible, has become widespread. Thus, composing and solving of the model examples is one of the most important stages for development and implementation of the economic and mathematical models. (11-18) The work presents setting and model example for the problem for selection of the investment sources and objects. The basic provisions of the economic and mathematical model are given bellow.

Let's assume that there is a set of potential projects $(i=1, \ldots, m)$, each of which is characterized by the following parameters:

1. $d_{\text {it }}-\mathrm{a}$ forecast income within the $\mathrm{t}^{\text {th }}$ year (the "year" can mean any fixed time stage within the account period) and $a_{i t}$ - required expenses within the $t^{\text {th }}$ year under $i^{\text {th }}$ project.

2. There is also a set of financing sources $(j=1, \ldots, n, j=0$ - self-financing or financing from own sources), for which the following values are determined:

3. $b_{j}-$ a maximum credit from the $\mathrm{j}^{\text {th }}$ source (as a rule, it depends on the interest rate for the credit and duration of the period, for which it is granted);

4. $b_{j}^{t}-$ a possible credit restriction by years $\left(t \in T_{0 j}\right)$;

5. $\alpha_{j}^{\mathrm{t}}-\mathrm{a}$ share of the required credit repayment for some projects and some years (for other projects and years it shall be taken as zero);

6. $p_{i t}-$ a rate of return for the $\mathrm{j}^{\text {th }}$ financing source within the $\mathrm{t}^{\text {th }}$ * year (to be determined by the creditor, and in case of $j=0$ (self-financing) it shall be currently taken as design value for the branch);

7. $g_{\mathrm{t}}-$ a share of the annual inflation.

At simultaneous profit accounting from the investments and inflation the discount coefficient shall be calculated by the following formula:

$$
q_{j}^{t}=\frac{1+p_{j t}}{1+g_{t}}
$$

Let's distinguish the following controlled variables of the model:

$-x_{j}^{\mathrm{t}}-$ share of the $\mathrm{j}^{\text {th }}$ credit within the $\mathrm{t}^{\text {th }}$ year;

$-z_{j}^{\mathrm{t}}$ - index of the real repayment for the $\mathrm{j}^{\text {th }}$ credit within the $\mathrm{t}^{\text {th }}$ year (value of maximum credit from the $\mathrm{j}^{\text {th }}$ financing source shall be taken as a basis $\left(b_{i}\right)$ ). This index can take a 
value both less, and greater than unity, as the value of the credit repayment within the $t^{\text {th }}$ year can exceed maximum value of the credit from the $\mathrm{j}^{\text {th }}$ source. For this reason the term "share" is not applicable for this index.

$-\varepsilon_{i}-$ selection of the $i^{\text {th }}$ project, $\varepsilon_{i}=0 \mathrm{~V} 1$ (selection of unknown parameter $\varepsilon_{i}$ is caused by the necessity of the decision to accept or not to accept of the $\mathrm{i}^{\text {th }}$ project due to resource limitation and for profit maximization).

Let's record the formula for calculation of values for obligatory and actual repayments of the $\mathrm{j}^{\text {th }}$ credit within the $\mathrm{t}^{\text {th }}$ year $\left(h_{j}^{t}\right.$ and $\left.w_{j}^{t}\right)$ accordingly by introduced controlled variables:

Basic limitations:

$$
\begin{gathered}
h_{j}^{t}=\alpha_{j}^{t} \times \sum_{t} x_{j}^{t} \times b_{j} ; \\
w_{j}^{t}=z_{j}^{t} \times b_{j} .
\end{gathered}
$$

$$
\begin{gathered}
\sum_{t} b_{j}^{t} \leq b_{j},(j=1, \ldots, n) . \\
\sum_{t} b_{j} \times x_{j}^{t} \leq b_{j},(j=1, \ldots, n) . \\
x_{j}^{t} \leq \frac{b_{j}^{t}}{b_{j}}, t \in T_{0 i} .
\end{gathered}
$$

Limitation (4) ensures selection of such value for the $\mathrm{j}^{\text {th }}$ credit within the $\mathrm{t}^{\text {th }}$ year, which would not be higher than the appropriate amount of possible credit restriction. In other words, a share of the credit from the $\mathrm{j}^{\text {th }}$ source per each year shall be such that would meet the credit value not exceeding the possible credit restriction per each year of the project implementation. The condition is valid only for the certain years $\left(t \in T_{0 i}\right)$ and sources of financing.

$$
x_{j}^{t} \geq 0, \forall j
$$

Condition (5) states that a share of the $\mathrm{j}^{\text {th }}$ credit within the $\mathrm{t}^{\text {th }}$ year shall be non-negative. Thus, conditions (3)-(5) restrict the controlled variable $x_{j}^{\tau}$ both below and above.

$$
w_{j}^{t} \geq h_{j}^{t} .
$$

Condition (6) states that value of actual repayment of the $\mathrm{j}^{\text {th }}$ credit within the $\mathrm{t}^{\text {th }}$ year shall not be less than the appropriate value of the obligatory repayment. Let's proceed to the controlled variable in this restriction using the formula for $h_{j}^{t}$ and $w_{j}^{t}$ having recorded previously:

$$
z_{j}^{t} \times b_{j} \geq \alpha_{j}^{t} \times \sum_{t} x_{j}^{t} \times b_{j}
$$

Having reduced the both parts of equation (7) by the value $b_{i}$ we obtain the following:

$$
z_{j}^{t} \geq \alpha_{j}^{t} \times \sum_{t} x_{j}^{t},(j=1, \ldots, n) .
$$

Certainly the value of actual repayment $w_{j}^{t}$ and, thus, index of actual repayment $z_{j}^{t}$ are non-negative: $z_{j}^{t} \geq 0$.

The condition of the credit repayment will be recorded in the following form:

$$
\sum_{\mathrm{t}} z_{j}^{\mathrm{t}} \times b_{j} \times\left(q_{j}^{\mathrm{t}}\right)^{T-t} \geq \sum_{t} x_{j}^{\mathrm{t}} \times b_{j} \times\left(q_{j}^{\mathrm{t}}\right)^{T-t},(j=1, \ldots, n),
$$


Or

$$
\sum_{\mathrm{t}} z_{j}^{\mathrm{t}} \times\left(q_{j}^{\mathrm{t}}\right)^{T-\mathrm{t}} \geq \sum_{\mathrm{t}} x_{j}^{\mathrm{t}} \times\left(q_{j}^{\mathrm{t}}\right)^{T-\mathrm{t}},(j=1, \ldots, n),
$$

where $\mathrm{T}$ - number of years within the account period (planning horizon).

Let's simplify the condition of the credit repayment introducing new value $y_{j}^{t}-$ an actual value of the credit from $\mathrm{j}^{\text {th }}$ source within the $\mathrm{t}^{\text {th }}$ year, $y_{j}^{t}=b_{j} \times x_{j}^{t}$. Then the credit repayment condition will be as follows:

$$
\sum_{t} w_{j}^{t} \times\left(q_{j}^{t}\right)^{T-t} \geq \sum_{t} y_{j}^{t} \times\left(q_{j}^{t}\right)^{T-t},(j=1, \ldots, n) .
$$

Let's denote the profit within the $\mathrm{t}^{\text {th }}$ year $\left(\Pi_{\mathrm{t}}\right)$ as a difference between arrivals $\left(Z_{\mathrm{t}}\right)$ and expenses $\left(U_{t}\right)$ within the appropriate year.

$$
\Pi_{t}=Z_{t}-U_{t}
$$

Arrivals and expenses within the $\mathrm{t}^{\text {th }}$ year shall be calculated by the following formula:

$$
\begin{aligned}
& Z_{t}=\sum_{j} y_{j}^{t}+\sum_{i} d_{i t} \times \varepsilon_{i}, \\
& U_{t}=\sum_{j} w_{j}^{t}+\sum_{i} a_{i t} \times \varepsilon_{i} .
\end{aligned}
$$

The formula show that arrivals within the $\mathrm{t}^{\text {th }}$ year are calculated as an amount of actual credit value obtained from all selected sources within the $\mathrm{t}^{\text {th }}$ year and income from all selected projects within the $\mathrm{t}^{\text {th }}$ year.

Accordingly, expenses within the $\mathrm{t}^{\text {th }}$ year consist of the repayment amounts within the $\mathrm{t}^{\text {th }}$ year of the credit taken out from the used sources and expenses by all selected investment projects within the same year.

It is obvious that for efficient functioning of the organization (company) its annual profit shall not be negative, i.e. reception of the funds (incomes) within each $t^{\text {th }}$ year considering retained profit within the previous periods shall overlap expenses within this year. Firstly this is associated with that the organization (company) shall constantly have free funds to cover its current expenses (salary payment, purchase of fixed assets and tangible assets, current credit debts for dividend payout to the shareholders, etc.). In view of the above said let's record the following condition, which shall be called "condition of nonnegativity for increased discounted profit within each $\mathrm{k}^{\text {th }}$ year":

$$
\Pi_{\mathrm{H}}^{\mathrm{K}}=\sum_{\mathrm{t}=1}^{k}\left(\sum_{j} x_{j}^{\mathrm{t}} \times b_{j}+\sum_{\mathrm{i}} d_{i t} \times \varepsilon_{i}-\sum_{i} a_{i t} \times \varepsilon_{i}-\sum_{j} w_{j}^{\mathrm{t}}\right) \times\left(q_{0}^{\mathrm{t}}\right)^{k-t} \geq 0,
$$

or

$$
\begin{gathered}
\Pi_{\mathrm{H}}^{\mathrm{K}}=\sum_{\mathrm{t}=1}^{k}\left(Z_{\mathrm{t}}-U_{\mathrm{t}}\right) \times\left(q_{0}^{\mathrm{t}}\right)^{k-t} \geq 0 . \\
q_{0}^{\mathrm{t}}=\frac{1+p_{0 t}}{1+g_{\mathrm{t}}},
\end{gathered}
$$

where $p_{0 t}-$ a standard rate (for the enterprise or the branch in general) of return on capital.

Newly introduced discount coefficient (17) has a small difference from the above mentioned coefficient. The substance of this difference consists in that the standard rate of return on capital, which is taken as average value of the enterprise or the branch in general, is used in new formula instead of discount rate (rate of return on credit). Mainly, it is calculated as average value from rates of return by the funds invested into this enterprise at different stages of its development. This index (average rate of return on the invested funds) 
is often used as a main criterion for determination of the financial stability and profitability of the organization. In other words, the creditor gives preference to the organization (company) with greater value of this index.

This formula is used for discounting of the profit received within the different time periods, by the fixed timing. In other words, in the course of time the retained profit changes its cost under influence of the rate of return on capital (the cost is increased, though funds could not be invested) and inflation (the cost is decreased).

As previously stated, the discounted profit (NPV - net present value) from the selected projects is taken as an optimization criterion. NPV takes a central position among indices for determination of investment project efficiency such as repayment period, profitability, rate of return on capital, etc. Let's record the criterion as follows:

$$
f=N P V(T)=\Sigma_{t}\left(Z_{t}-U_{t}\right) \times\left(q_{0}^{t}\right)^{T-t} \rightarrow \max
$$

The optimum values of the controlled variables $x_{j}^{\mathrm{t}}, z_{j}^{\mathrm{t}}, \varepsilon_{i}$ are obtained in the points of the set of all possible values for these variables, which maximize the criterion. In other words, the optimum values of the controlled variables will correspond to maximum value of the profit from the selected projects (from all or their part).

\section{Model Example}

Let's assume that there are two financing sources $(n=2)$, for which the following is known: maximum credit amounts from the appropriate source $\left(b_{i}\right)$, rates of return on the credit $\left(p_{j}\right)$, possible credit restrictions by years $\left(b_{j}^{t}\right)$. Planning horizon -3 years. For the first source $b_{1}$ $=1000 \mathrm{MU}, p_{1}=0.25$; for the second source $b_{2}=2000 \mathrm{MU}, p_{2}=0.30, b_{2}^{1}=1000 \mathrm{MU}, b_{2}^{2}$ $=500 \mathrm{MU}, b_{2}^{3}=500 \mathrm{MU}$. Thus, possible credit restrictions from the 2 nd source by years are as follows: within the first year $1000 \mathrm{MU}$ maximum, within the second and third years $500 \mathrm{MU}$ maximum. For the first financing source there is no credit restriction by years. The credit shall be completely repaid not later than within the third year of the selected investment project implementation.

Moreover, there are 4 investment projects, which could be implemented (not alternative). Implementation of all selected projects starts within the first year of the account period simultaneously. For these projects the following is specified: forecast expenses and their breakdown by years of the project implementation and the forecast incomes. Data concerning the investment projects are given in Table 1.

Table 1. Input Data for the Investment Projects

\begin{tabular}{|c|c|c|c|c|c|c|c|}
\hline \multirow{3}{*}{ Projects } & \multicolumn{4}{|c|}{ Forecast Expenses $a_{i t}, \mathrm{MU}$} & \multicolumn{3}{|c|}{ Forecast Income $d_{i t}, \mathrm{MU}$} \\
\hline & \multirow[b]{2}{*}{ Total } & \multicolumn{3}{|c|}{ Breakdown by Years } & \multirow[b]{2}{*}{$\begin{array}{c}1 \mathrm{st} \\
\text { year }\end{array}$} & \multirow[b]{2}{*}{$\begin{array}{l}\text { 2nd } \\
\text { year }\end{array}$} & \multirow[b]{2}{*}{ 3rd year } \\
\hline & & $\begin{array}{c}1 \mathrm{st} \\
\text { year }\end{array}$ & $\begin{array}{l}2 \text { nd } \\
\text { year }\end{array}$ & $\begin{array}{c}\text { 3rd } \\
\text { year }\end{array}$ & & & \\
\hline 1 & 1500 & 700 & 500 & 300 & 0 & 600 & 1500 \\
\hline 2 & 1000 & 300 & 300 & 400 & 100 & 200 & 1000 \\
\hline 3 & 2000 & 1000 & 500 & 500 & 300 & 0 & 2100 \\
\hline 4 & 1000 & 500 & 300 & 200 & 0 & 400 & 1000 \\
\hline
\end{tabular}

Design (average) rate of return on capital for the enterprise shall be taken as $0.15\left(p_{0}=\right.$ $0.15)$. Let's consider that within the limits of the account period inflation is constant and equal to $5 \%$ per annum $(g=0.05)$.

The optimum solution shall be found during heuristic generation of the controlled variables $\varepsilon_{i}$. This means that for ease of the model calculations the vector $\varepsilon$ (project 
selection) shall be taken as $\left(\varepsilon=\varepsilon^{0}\right)$. Moreover, it is considered that the expenses under the projects have not exceeded maximum amount of the credit amount from the available sources. Considering this the possible variants of the vector $\varepsilon^{0}$ are as follows: $(1 ; 1 ; 0 ; 0)$, $(0 ; 1 ; 1 ; 0),(1 ; 0 ; 0 ; 1),(0 ; 1 ; 0 ; 1),(0 ; 0 ; 1 ; 1)$. The optimum solution and its own criterion (value of the target function) will correspond to each variant of vector $\varepsilon^{0}$ It is obvious that finally the vector, at which the value for optimization criterion will be maximum when fulfilling all other restrictions, will be preferred. In this example vector $\varepsilon^{0}=(1 ; 1 ; 0 ; 0)$ shall be taken, i.e. all calculations are performed considering selection of only first two projects. As Table 1 shows the total expenses for the selected first two projects are $2500 \mathrm{MU}$. Maximum credit amount from both sources is equal to $3000 \mathrm{MU}$. It is obvious that implementation of these projects is possible in terms of financing sufficiency from the external sources.

\section{What Does Investor (Decision Maker) Control?}

The controlled variables have been introduced above, let's record them one more time. $x_{j}^{\mathrm{t}}$ - share of the $\mathrm{j}^{\text {th }}$ credit within the $\mathrm{t}^{\text {th }}$ year; $z_{j}^{\mathrm{t}}$-index for repayment of the $\mathrm{j}^{\text {th }}$ credit within the $\mathrm{t}^{\text {th }}$ year.

Firstly calculate the discount coefficients for each financing source considering the rate of return on credit (rate of return on capital) and share of inflation using formula 1, 17 for calculation of the reduction coefficients.

$$
q_{1}=\frac{1+0,25}{1+0,05}=1,19, q_{2}=\frac{1+0,3}{1+0,05}=1,24, q_{0}=\frac{1+0,15}{1+0,05}=1,1 \text {. }
$$

Let's record restrictions for the controlled variables:

1. $\sum_{\mathrm{t}} x_{j}^{t} \leq 1: x_{11}+x_{12}+x_{13} \leq 1, x_{21}+x_{22}+x_{23} \leq 1$.

2. $x_{j}^{t} \leq \frac{b_{j}^{t}}{b_{j}}: x_{21} \leq \frac{1000}{2000}=0,5 ; x_{22} \leq \frac{500}{2000}=0,25 ; x_{23} \leq \frac{500}{2000}=0,25$.

3. $\sum_{\mathrm{t}} z_{j}^{t} \times\left(q_{j}^{t}\right)^{T-t} \geq \sum_{t} x_{j}^{t} \times\left(q_{j}^{t}\right)^{T-t}$,

$j=1: z_{11} \times 1,19^{2}+z_{12} \times 1,19+z_{13} \geq x_{11} \times 1,19^{2}+x_{12} \times 1,19+x_{13}$,

$j=2: z_{21} \times 1,24^{2}+z_{22} \times 1,24+z_{23} \geq x_{21} \times 1,24^{2}+x_{22} \times 1,24+x_{23}$.

Simplify these restrictions:

$z_{11} \times 1,42+z_{12} \times 1,19+z_{13} \geq x_{11} \times 1,42+x_{12} \times 1,19+x_{13}$,

$z_{21} \times 1,54+z_{22} \times 1,24+z_{23} \geq x_{21} \times 1,54+x_{22} \times 1,24+x_{23}$.

4. The condition of nonnegativity of increased discounted profit per each year:

$t=1: x_{11} \times 1000+x_{21} \times 2000-z_{11} \times 1000-z_{21} \times 2000 \geq 900$,

$t=2$ :

$x_{12} \times 1000+x_{22} \times 2000-z_{12} \times 1000-z_{22} \times 2000+\left(x_{11} \times 1000+\right.$

$\left.x_{21} \times 2000-z_{11} \times 1000-z_{21} \times 2000-900\right) \times 1,1 \geq 0$

5. $x_{j}^{t} \geq 0, z_{j}^{t} \geq 0, \forall j, t$.

Optimization criterion (target function) shall be recorded in the following form:

$N P V(T)=\sum_{t}\left(\sum_{j} b_{j} \times x_{j}^{t}-\sum_{j} w_{j t}\right) \times\left(q_{0}^{t}\right)^{T-t}+\sum_{t}\left[\sum_{i}\left(d_{i t} \times \varepsilon_{i}-a_{i t} \times \varepsilon_{i}\right)\right] \times\left(q_{0}^{t}\right)^{T-t} \rightarrow$ $\max$

At fixed vector of the project selection $\left(\varepsilon=\varepsilon^{0}\right)$ the second summand in the target function is a constant, as the investment projects are not selected during solving the optimization problem. Let's denote this constant via $A_{0}$. Then:

$A_{0}=\sum_{t}\left[\sum_{i}\left(d_{i t} \times \varepsilon_{i}-a_{i t} \times \varepsilon_{i}\right)\right] \times\left(q_{0}^{t}\right)^{T-t}$. The target function will be recorded as follows:

$N P V(T)=\sum_{t}\left(\sum_{j} b_{j} \times x_{j}^{t}-\sum_{j} z_{j t} \times b_{j}\right) \times\left(q_{0}^{t}\right)^{T-t}+A_{0} \rightarrow \max$. 
When recording the linear programming problem constant $A_{0}$ is omitted, as the target function shall not contain absolute terms (constants). And upon finding the optimum solution the above mentioned constant shall be added to the obtained value of the target function.

Thus, in relation to the example, the criterion is as follows:

$x_{11} \times 1000 \times 1,1^{2}+x_{12} \times 1000 \times 1,1+x_{13} \times 1000+x_{21} \times 2000 \times 1,1^{2}+$

$x_{22} \times 2000 \times 1,1+x_{23} \times 2000-z_{11} \times 1000 \times 1,1^{2}-z_{12} \times 1000 \times 1,1-$

$z_{13} \times 1000-z_{21} \times 2000 \times 1,1^{2}-z_{22} \times 2000 \times 1,1-z_{23} \times 2000 \rightarrow \max$

Simplify the equation:

$1210 \times x_{11}+1100 \times x_{12}+1000 \times x_{13}+2420 \times x_{21}+2200 \times x_{23}-1210 \times z_{11}-$

$1100 \times z_{12}-1000 \times z_{13}-2420 \times z_{21}-2200 \times z_{22}-2000 \times z_{23} \rightarrow \max$

Let's come to the single-index variables for standard recording of the linear programming problem appearing as follows:

$W \times X+V \times \varepsilon \leq b_{1}, X \geq 0, \varepsilon=0$ V 1 ,

$F=C \times X \rightarrow \max$,

where $W, V, C, b_{1}$ - some known matrices; $X$ - matrix of control variables; $\varepsilon$ - project selection vector.

Let's assume that:

$x_{11}=X_{1} ; z_{11}=X_{7}$;

$x_{12}=X_{2} ; z_{12}=X_{8}$;

$x_{13}=X_{3} ; z_{13}=X_{9}$;

$x_{21}=X_{4} ; z_{21}=X_{10}$;

$x_{22}=X_{5} ; z_{22}=X_{11}$;

$x_{23}=X_{6} ; z_{23}=X_{12}$.

Record the linear programming problem:

$X_{1}+X_{2}+X_{3} \leq 1$,

$X_{4}+X_{5}+X_{6} \leq 1$,

$X_{4} \leq 0,5$,

$X_{5} \leq 0,25$,

$X_{6} \leq 0,25$,

$1,42 X_{1}+1,19 X_{2}+X_{3}-1,42 X_{7}-1,19 X_{8}-X_{9} \leq 0$

$1,54 X_{4}+1,24 X_{5}+X_{6}-1,54 X_{10}-1,24 X_{11}-X_{12} \leq 0$,

$1000 X_{1}+2000 X_{4}-1000 X_{7}-2000 X_{10} \geq 900$,

$1100 X_{1}+1000 X_{2}+2200 X_{4}+2000 X_{5}-1100 X_{7}-1000 X_{8}-2200 X_{10}-2000 X_{11} \geq$ 990

$1210 \times X_{1}+1100 \times X_{2}+1000 \times X_{3}+2420 \times X_{4}+2200 \times X_{5}+2000 \times X_{6}-$

$1210 \times X_{7}-1100 \times X_{8}-1000 \times X_{9}-2420 \times X_{10}-2200 \times X_{11}-2000 \times X_{12} \rightarrow$ $\max$

The conditions of nonnegativity for the controlled variables are standard for the linear programming problem, thus, they shall not be recorded in the example. Thus, we obtain the linear programming problem with 12 variables and 9 restrictions. The target function is maximized. The obtained problem we solves by means of any standard software package 
intended for these purposes. In our case the optimum solution shall be found by means of software SIMPLGUS.

As a result of the problem solving we have obtained six optimum solutions, each of which maximizes the target function (optimization criterion). Three of them are given below. The calculation results of the program are given in Table 2.

Table 2. Optimum Problem Solving

\begin{tabular}{|c|c|c|c|c|c|c|c|}
\hline \multirow[t]{2}{*}{ No. } & \multirow{2}{*}{$\begin{array}{l}\text { Financin } \\
\mathrm{g} \\
\text { Sources }\end{array}$} & \multicolumn{3}{|c|}{$\begin{array}{c}\text { Financing Shares }\left(x_{j}^{\mathrm{t}}\right) . \\
\text { Financing Values }\left(y_{j}^{\mathrm{t}}\right), \mathrm{MU}\end{array}$} & \multicolumn{3}{|c|}{$\begin{array}{c}\text { Repayment Index }\left(z_{j}^{t}\right) . \\
\text { Repayment Values }\left(w_{j}^{t}\right), \text { MU }\end{array}$} \\
\hline & & 1st year & 2nd year & 3rd year & 1st year & 2nd year & $3 \mathrm{rd}$ year \\
\hline \multirow{2}{*}{1} & $1 \mathrm{st}$ & $\begin{array}{c}1 \\
1000\end{array}$ & $\begin{array}{l}0 \\
0\end{array}$ & $\begin{array}{l}0 \\
0\end{array}$ & $\begin{array}{l}0 \\
0\end{array}$ & $\begin{array}{l}0 \\
0\end{array}$ & $\begin{array}{c}1.42 \\
1420\end{array}$ \\
\hline & 2nd & $\begin{array}{c}0.5 \\
1000\end{array}$ & $\begin{array}{c}0.25 \\
500\end{array}$ & $\begin{array}{c}0.25 \\
500\end{array}$ & $\begin{array}{c}0.55 \\
1100\end{array}$ & $\begin{array}{c}0.5 \\
1000\end{array}$ & $\begin{array}{c}0.173 \\
346\end{array}$ \\
\hline \multirow{2}{*}{2} & $1 \mathrm{st}$ & $\begin{array}{c}1 \\
1000\end{array}$ & $\begin{array}{l}0 \\
0\end{array}$ & $\begin{array}{l}0 \\
0\end{array}$ & $\begin{array}{l}0 \\
0\end{array}$ & $\begin{array}{l}0 \\
0\end{array}$ & $\begin{array}{l}1.42 \\
1420\end{array}$ \\
\hline & 2nd & $\begin{array}{l}0 \\
0\end{array}$ & $\begin{array}{l}0.25 \\
500\end{array}$ & $\begin{array}{c}0.25 \\
500\end{array}$ & $\begin{array}{c}0.05 \\
100\end{array}$ & $\begin{array}{c}0.25 \\
500\end{array}$ & $\begin{array}{c}0.173 \\
346\end{array}$ \\
\hline \multirow{2}{*}{3} & $1 \mathrm{st}$ & $\begin{array}{c}1 \\
1000 \\
\end{array}$ & $\begin{array}{l}0 \\
0\end{array}$ & $\begin{array}{l}0 \\
0 \\
\end{array}$ & $\begin{array}{l}0 \\
0 \\
\end{array}$ & $\begin{array}{l}0 \\
0 \\
\end{array}$ & $\begin{array}{c}1.42 \\
1420 \\
\end{array}$ \\
\hline & 2nd & $\begin{array}{l}0 \\
0\end{array}$ & $\begin{array}{l}0.25 \\
500\end{array}$ & $\begin{array}{c}0.077 \\
154\end{array}$ & $\begin{array}{c}0.05 \\
100\end{array}$ & $\begin{array}{c}0.25 \\
500\end{array}$ & $\begin{array}{l}0 \\
0\end{array}$ \\
\hline
\end{tabular}

The criterion negativity is conditioned by the fact that the forecast income and expenses under the project have not been considered in the target function record. Thus, in order to obtain actual value of net discounted profit, the discounted difference between income and expenses under all selected projects per each year shall be added to the value of the target function. Let's consider optimum solutions and analyze them. As the table shows, the program offers a single possible optimum solution at the specified parameters with regard to the first financing source. It consists in that the whole possible amount of the credit from this source $(1000 \mathrm{MU})$ is taken immediately within the first implementation of the projects and repaid within the last year in the amount of $1420 \mathrm{MU}$. This variant is obvious, because the rate of return on the first financing source is significantly lower that the appropriate rate for the second source. For the investor it is profitable to firstly use those funds, which are cheaper for it. The second source is more expensive, therefore, the investor (decision makers) uses it secondly in case of insufficiency of the cheaper source. Moreover, the necessity of its quickest repayment is obvious. Here the program offers several alternative solutions, which have one common disadvantage. As the table shows an absurd situation consisting in that the credit repayment anticipates its taking is observed in the solutions. Actually, the first solution shows that the credit amount of $1000 \mathrm{MU}$ taken within the first year is repaid within this period in the amount of $1100 \mathrm{MU}$, thus creating reserve for loans for the future periods. It is obvious that providing discounting for funds reception and outflow such situation is profitable for the organization, but it doesn't take place in real credit and monetary relations.

The second optimum solution provides the similar situation. In this case by the second financing source the credit is taken within the second year of the project implementation, and repayment of this source starts from the first year. The third solution with insignificant changes is the same as the first two. As a result the situation takes place, when the discounted cash flow for this financing source becomes unprofitable for the creditor, and in its turn loss-free for the investor. Under these conditions none of the creditors will be 
interested in the funds granting on credit. The fact, that the first financing source is sufficient for implementation of the selected investment projects, becomes obvious Actually, considering the forecast profit per each year the scarcity of funds under the two selected projects is 900 and 100 MU accordingly within the first and second year of their implementation. But maximum credit amount from the first source is equal to $1000 \mathrm{MU}$.

Based on the above mentioned data it follows that it is necessary to introduce additional restrictions for credit repayment. One of such restrictions will be restriction for maximum amount of credit repayment per each $\mathrm{k}^{\text {th }}$ year, which shall not exceed the increased discounted amount of the credit within k-1 years. It is obvious that under these conditions within the first year the credit repayment value is equal to zero. Record the restriction as follows:

$$
\left\{\begin{array}{c}
w_{j}^{k} \leq \sum_{t=1}^{k-1} x_{j}^{t} \times b_{j} \times\left(q_{j}\right)^{k-t}, k \neq 1, \\
w_{j}^{k}=0, k=1,
\end{array}\right.
$$

where $w_{j}^{k}-$ value of the $\mathrm{j}^{\text {th }}$ credit repayment within the $\mathrm{k}^{\text {th }}$ year.

Considering that $w_{j}^{k}=z_{j}^{k} \times b_{j}$ and reducing the both parts of equation by value $b_{i}$ we obtain the following:

$$
\left\{\begin{array}{c}
z_{j}^{k} \leq \sum_{t=1}^{k-1} x_{j}^{t} \times\left(q_{j}\right)^{k-t}, k \neq 1, \\
z_{j}^{k}=0, k=1 .
\end{array}\right.
$$

\section{Results of scientific research}

The following shall be distinguished as basic resulting provisions of the research. Firstly, when setting the problem we presume that selection of the optimum investment solution is limited to selection of the investment sources and objects (investment projects). Moreover, both the investment sources and the projects are characterized by input parameters being forecast values.

Secondly, "share of financing from the source" and "index of actual repayment of the source" are distinguished as the controlled variables in the model. Moreover, an additional controlled variable "project selection" being the vector, each coordinate of which can take binary value 0 or 1 , is introduced. The controlled variable is responsible for acceptance or rejection of each project in the investment portfolio due to resource limitation and necessity to maximize the total reduced profit.

Thirdly, problem setting provides imposition of the restrictions on the controlled variables providing determination of the top and bottom limit for "share of financing from the source", the condition of the credit debts repayment by each financing source, etc.

Fourthly, a net discounted income from implementation of the investment projects included into the portfolio is proposed as an optimization criterion for the problem for optimum investment solution selection.

Fifthly, the model example developed for the problem has allowed correcting the initial record of economic and mathematical models supplementing it with the restriction for financing source repayment, which substance consists in that the top limit is set for the amount of financing source repayment within each year corresponding to the increased discounted amount of the credit within the previous years.

\section{Conclusion}


The problem of the optimum investment solution selection can be presented as the linear programming problem, in which the controlled variables are generated by heuristic method. The economic and mathematical model is approved and improved using the model examples simulating the real economic processes.

In general the model examples favourably influence the modelling process assisting in detection of hidden "weak points" and "underlying potential problems" of the mathematical models. Moreover, they help for the scientist to more deeply enter into the modelled processes and understand their details. The whole above mentioned information is significantly associated with the modelling of micro- and macroeconomic processed.

\section{References}

1. S. Zakharin, S. Stoyanova-Koval, I. Kychko, V. Marhasova, I. Shupta, Strategic management of the investment process in the agricultural sector (for example, agricultural enterprises and the food industry), Journal of Optimization in Industrial Engineering 14, 209 (2021)

2. Y. Aleskerova, T. Zoia, H. Skrypnyk, O. Grytsyna, Modeling the level of investment attractiveness of the agrarian economy sector, International Journal of Industrial Engineering and Production Research 31, 647 (2020)

3. V. Babenko, N. Chebanova, N. Ryzhikova, S. Rudenko, N. Birchenko, Research into the process of multi-level management of enterprise production activities with taking risks into consideration, Eastern-European Journal of Enterprise Technologies 1, 4 (2018)

4. H. Seyyedhasani, J. S. Dvorak, Reducing fieldwork time using fleet routing optimization, Biosystems Engineering 169, 1 (2018)

5. C. G. Sorensen, D. D Bochtis, Conceptual model of fleet management in agriculture, Biosystems Engineering 105, 41 (2010)

6. A. Sopegno, A. Calvo, R. Berruto, P. Busato, D. Bocthis, A web mobile application for agricultural machinery cost analysis, Computers and Electronics in Agriculture 130, 158 (2016)

7. N. G. Vovchenko, A. A. Alukhanyan, L. Y. Andreeva, G. A. Buryakov, Formation of an adaptive personnel training system as a factor of ensuring the financial stability of leasing companies, European Research Studies Journal 21, 3 (2018)

8. S. Shepelev, V. Shepelev, Z. Almetova, Optimization of Technical Equipment for Crop Sowing Processes, Procedia Engineering 150, 1258 (2016)

9. D. Bochtis, C. G. Sorensen, D. Kateris, Choosing a Machinery System, Operations Management in Agriculture, 117 (2019)

10. D. D. Bochtis, C. G. Sorensen, P. Busato, Advances in agricultural machinery management: A review, Biosystems Engineering 126, 69 (2014)

11. G. Smirnova, R. Sabitov, B. Morozov, S. Sabitov, N. Elizarova, To the problem of dynamic modelling and management in an integrated environment of the industrial cluster, IFAC-PapersOnline 48, 1230 (2015)

12. M. Karunarathna, C. Wilson, Agricultural biodiversity and farm-level technical efficiency: An empirical investigation, Journal of Forest Economics 29, 38 (2017)

13. P. Luukka, M. Collan, New fuzzy insurance pricing method for giga-investment project insurance, Insurance: Mathematics and Economics 65, 22 (2015)

14. Chi-Chuan Lee, Chien-Chiang Lee, Yan-Yu Chiou, Insurance activities, globalization, and economic growth: New methods, new evidence, Journal of International Financial Markets, Institutions and Money 51, 155 (2017)

15. G. Reina, A. Milella, R. Galati, Terrain assessment for precision agriculture using vehicle dynamic modelling, Biosystems Engineering 162, 124 (2017) 
16. Y. Hu, Y. Liu, Z. Wang, J. Wen, J. Lu, A two-stage dynamic capacity planning approach for agricultural machinery maintenance service with demand uncertainty, Biosystems Engineering 190, 201 (2020)

17. R. C. Tieppo, T. L. Romanelli, M. Milan, C. G. Sorensen, D. Bochtis, Modelling cost and energy demand in agricultural machinery fleets for soybean and maize cultivated using a no-tillage system, Computers and Electronics in Agriculture 156, 282 (2019)

18. A. Vafador, M. Tolouei-Rad, K. Hayward, K. Abhary Technical feasibility analysis of utilizing special purpose machine tools, Journal of Manufacturing Systems 39, 53 (2016) 